Sharif University of Technology
Scientia Iranica
SCIENTIA
IRAN I CA
http://scientiairanica.sharif.edu

\title{
Streamflow map of the Eastern Black Sea Region, Turkey
}

\author{
E. Eris ${ }^{a, *}$ and N. Agiralioglu ${ }^{b, 1}$ \\ a. Department of Civil Engineering, Ege University, Bornova, Izmir, 35100 Turkey. \\ b. Hydraulics Laboratory, Faculty of Civil Engineering, Istanbul Technical University, Maslak, Istanbul, 34469 Turkey. \\ Received 4 February 2016; received in revised form 14 September 2016; accepted 14 January 2017
}

\section{KEYWORDS \\ Streamflow map; Ordinary kriging; Universal kriging; Simple regression; Eastern Black Sea Region.}

\begin{abstract}
The purpose of this study is to generate a streamflow map for the coastal part of the Eastern Black Sea Region, which is located in the north-east of Turkey. The topographic structure of the region is an obstacle in terms of the number of observation gauges. In order to determine spatial variation of flow and to estimate flow on any ungauged points in the region, interpolation between gauged and ungauged points is applicable. For this purpose, any hydrological models, which depend on large meteorological datasets, can be used. However, in this study, ordinary and universal kriging as geostatistical interpolation methods are used to interpolate mean annual flow depth over the study area; thus, flow values on ungauged points can be easily estimated. Kriging methods are compared with simple regression based on the relationship between flow data and basin area. Calibration results of the observed and estimated flow depths for ordinary and universal kriging methods are satisfactory; the determination coefficients are found to be 0.84 and 0.87 , respectively. Besides, the validation results show that the performance of kriging methods is superior to that of the regression model.
\end{abstract}

(C) 2018 Sharif University of Technology. All rights reserved.

\section{Introduction}

Spatially distributed hydrological models provide more cost-effective means for determining water potential assessment within a basin; however, the accuracy of model results strongly depends on the accuracy of model inputs, particularly precipitation observations. In mountainous regions, most of the precipitation observations usually have $30 \%$ or higher error, whereas streamflow errors vary from $5 \%$ to $10 \%-15 \%$ [1]. In addition, the number of observation gauges is limited

1. Present address: Department of Civil Engineering, Antalya Bilim University, Antalya, 07190, Turkey

*. Corresponding author. Tel.: +90 232 3115041 ; Fax: +90 232 3425629

E-mail addresses: ebru.eris@ege.edu.tr (E. Eris); necati.agiralioglu@antalya.edu.tr (N. Agiralioglu)

doi: $10.24200 /$ sci.2017.4261 in developing countries. Besides, in cases where spatial streamflow estimation for longer periods such as monthly, seasonal, or annual scale is required, simpler relationships may prove sufficient approximation [2]. In order to avoid the complexity of hydrological models, which depend on accurate and large meteorological dataset, available flow observation data can be used for determining spatial variation of streamflow.

Spatial variability of flow has been represented by various techniques. For instance, flow depth has been defined as a regionalized phenomenon that uses a centroid based method by performing ordinary kriging to predict long-term streamflows corresponding to different exceedance probabilities over space and time [2]. The method locating gauged flow values at the centroids of the basins has previously been used for runoff mapping [3-5]. This approach has also been used for flood regionalization [6]. The main idea in this study is that spatial proximity is a significantly 
better estimator of regional flood frequencies than basin attributes are.

The total area in mapping can sometimes be divided into fundamental units, i.e. sub-dividing a larger basin into sub-drainage basins or into a regular grid network. The drainage basins can be defined by points in space and, during the mapping processes, average of the runoff from all the sub-drainage basins that fall within a grid cell is used. A disadvantage of this method is that some cells do not include observation points. To overcome this problem, a deterministic interpolation is applied and used as the Triangulated Irregular Network (TIN) technique (i.e., linear interpolation within the TIN facets, represented by the gauging station, which has been considered as nodes) [7].

Other studies are based on disaggregation and covariance approaches [8,9]. These approaches were developed for mapping annual runoff along the river network using water balance constraints in the estimations [10]. They were subsequently extended, generalized, and applied to mean annual runoff coupled with empirical relations presented by an application to assess water resources in France [11]. Effects of local features such as karst and river regulations were then added into this approach to produce the maps of mean runoff for France [12].

Top-kriging (topological kriging) was presented in ungauged catchments [13] as a method to estimate streamflow-related variables. The concept was built [10] and extended in a number of ways. Although the method was tested for the 100-year flood case in two Austrian regions, it can be used to spatially interpolate a range of streamflow-related variables such as mean annual flow, low flow, and flood characteristics, and it provides more robust estimates than regional regression models do [14]. Top-kriging has recently been used to estimate flood quantiles and flow duration curves for ungauged sites and has been compared with canonical kriging and regression equations $[15,16]$. Block kriging was coupled with water balance and data uncertainty analyses to estimate mean annual runoff for a large basin in China [17].

In this study, the aim is to determine spatial variation of flow for the coastal part of the Eastern Black Sea Region, Turkey, as such a study is not available for the region. Considering that the region has a significant hydropower potential [18], it is important to know the flow at ungauged points. The coastal part of the Eastern Black Sea Region is mountainous such that most of the precipitation observation stations are located in the valley floors and they could not represent orographic precipitation characteristics of the region [19]. Because of this, use of any hydrological model based on precipitation data is not convenient to determine flow variability in the study area. In order to produce a streamflow map, a previous study [2], which is based on kriging application for different exceedance probabilities of streamflow estimation, is followed. The difference of this study from the previous one is the use of mean annual flow observation data instead of flow data corresponding to different exceedance probabilities. Besides, this study includes a universal kriging application to produce streamflow map for the coastal part of the Eastern Black Sea Region.

\section{Study area and data}

The study area is the coastal part of the Eastern Black Sea Region, which is situated in the north-east of Turkey, between the coordinates $40^{\circ} 31^{\prime}-41^{\circ} 24^{\prime}$ North and $38^{\circ} 08^{\prime}-41^{\circ} 26^{\prime}$ East. This coastal part can be defined as the region between the Eastern Black Sea Mountain chain and the Black Sea (Figure 1). The Eastern Black Sea Mountain chain is parallel to the

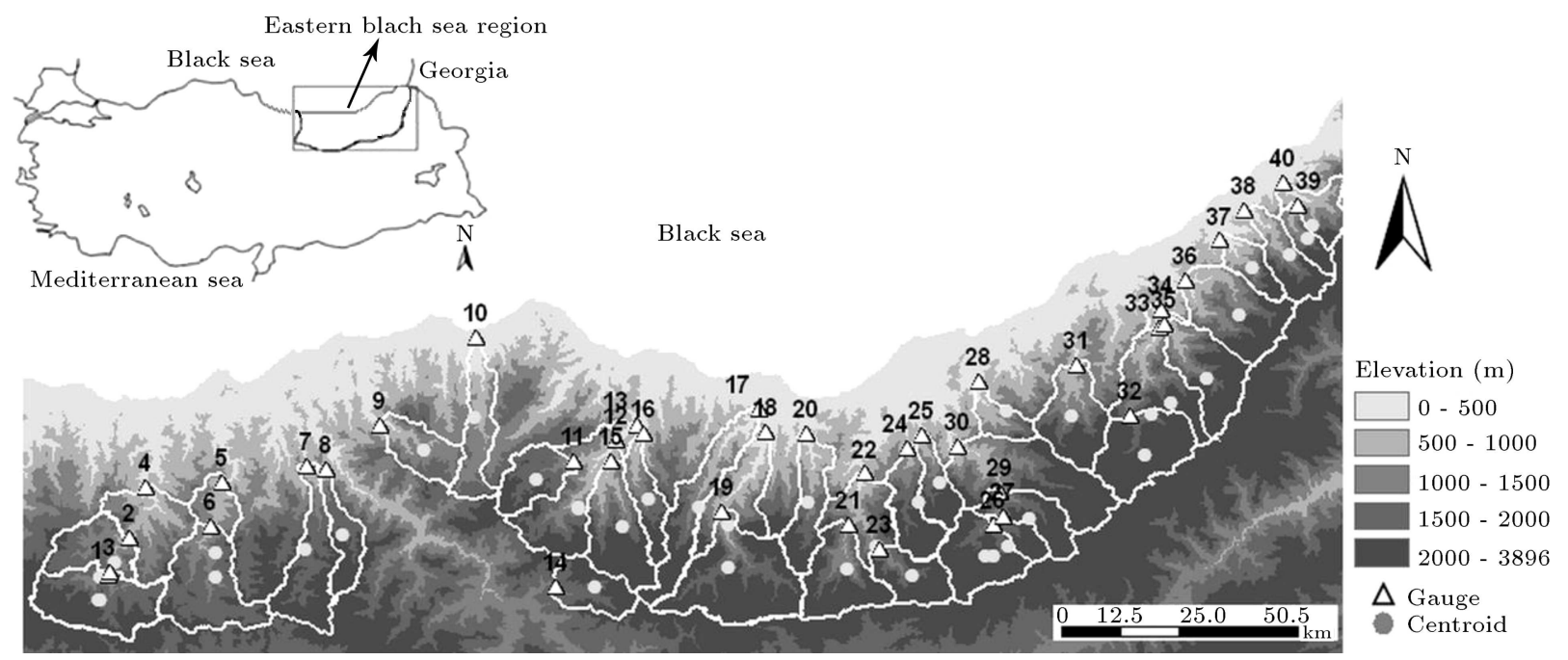

Figure 1. Study area and flow gauges with basin boundaries. 
Table 1. Area and elevation of the flow gauges.

\begin{tabular}{|c|c|c|c|c|c|c|c|c|c|}
\hline No & $\begin{array}{c}\text { Gauge } \\
\text { name }\end{array}$ & $\begin{array}{c}\text { Area } \\
\left(\mathrm{km}^{2}\right)\end{array}$ & $\begin{array}{c}\text { Elevation } \\
(\mathrm{m})\end{array}$ & $\begin{array}{c}\text { Record } \\
\text { period }\end{array}$ & No & $\begin{array}{c}\text { Gauge } \\
\text { name }\end{array}$ & $\begin{array}{c}\text { Area } \\
\left(\mathrm{km}^{2}\right)\end{array}$ & $\begin{array}{c}\text { Elevation } \\
(\mathrm{m})\end{array}$ & $\begin{array}{c}\text { Record } \\
\text { period }\end{array}$ \\
\hline 1 & Ikisu & 317.2 & 1037 & 1986-1999 & 21 & Alcakkopru & 243 & 700 & $1979-2005$ \\
\hline 2 & Alancik & 470.2 & 700 & $1986-2004$ & 22 & Ulucami & 576.8 & 260 & $1979-2005$ \\
\hline 3 & Ikisu & 292.7 & 990 & $1965-1974$ & 23 & Serah & 154.7 & 1170 & $1966-2001$ \\
\hline 4 & Dereli & 713 & 248 & $1962-2004$ & 24 & Yenikoy & 171.6 & 470 & $1982-2004$ \\
\hline 5 & Tuglacik & 397.9 & 400 & $1986-2006$ & 25 & Cevizlik & 115.9 & 400 & 1982-2002 \\
\hline 6 & Sinirkoy & 296.9 & 650 & $1983-2005$ & 26 & Toskoy & 223.1 & 1296 & $1965-2002$ \\
\hline 7 & Hasanseyh & 256.8 & 370 & $1984-2006$ & 27 & Toskoy & 284.3 & 1210 & $1986-2001$ \\
\hline 8 & Suttasi & 124.9 & 188 & $1970-2004$ & 28 & Komurculer & 83.3 & 250 & 1984-2002 \\
\hline 9 & CucenKopru & 162.7 & 240 & $1980-2006$ & 29 & Derekoy & 445.2 & 942 & 1966-2002 \\
\hline 10 & Bahadirli & 191.4 & 17 & $1962-2002$ & 30 & Simsirli & 834.9 & 308 & 1988-2004 \\
\hline 11 & Ormanustu & 150 & 770 & 1985-1999 & 31 & Kaptanpasa & 231.2 & 480 & 1984-2006 \\
\hline 12 & Kanlipelit & 708 & 257 & 1951-1989 & 32 & Cat & 277.6 & 1250 & 1982-1999 \\
\hline 13 & Ogutlu & 728.4 & 160 & 1984-2004 & 33 & Konaklar & 496.7 & 300 & $1980-2005$ \\
\hline 14 & Ikisu & 149.6 & 1450 & 1984-1999 & 34 & Topluca & 762.3 & 233 & 1964-2002 \\
\hline 15 & Ortakoy & 261 & 380 & $1980-2002$ & 35 & Mikronkopru & 239.2 & 370 & 1980-2004 \\
\hline 16 & Ciftdere & 121.5 & 250 & $1980-2006$ & 36 & Kemerkopru & 302.2 & 230 & $1984-1997$ \\
\hline 17 & Findikli & 258.6 & 90 & $1979-2004$ & 37 & Arili & 92.15 & 150 & $1982-2005$ \\
\hline 18 & Agnas & 635.7 & 78 & 1944-2002 & 38 & Koprubasi & 156 & 60 & $1966-2003$ \\
\hline 19 & Aytas & 421.2 & 510 & $1979-2005$ & 39 & Kucukkoy & 66.37 & 310 & $1985-2006$ \\
\hline 20 & Ortakoy & 173.6 & 150 & $1979-2006$ & 40 & Baskoy & 186.2 & 75 & $1978-2006$ \\
\hline
\end{tabular}

coast as the north boundary of the study area, and it rises to more than $3000 \mathrm{~m}$ above msl (mean sea level). The Black Sea Region has a rocky steep coast [20].

Humid and mild climate dominates the coastal area of the Eastern Black Sea Region. Yearly average temperature in the coastline is about $14-15^{\circ} \mathrm{C}$; however, it decreases with increasing elevation. Snowfall can be seen in winter. The mean precipitation of the coastal part of the study area is more than $1000 \mathrm{~mm}$, and in many points it exceeds $2000 \mathrm{~mm}$.

Mean annual flow observations from 40 flow gauges are used in this study. Locations of the gauges are shown in Figure 1. Area and elevations of the flow gauges are given in Table 1 . "No" column in Table 1 corresponds to numbers on the map in Figure 1.

The flow observation record length varies from 10 to 49 between years 1944 and 2006 with some gaps in the data. In order to complete a gap in any gauge record, regression equations were generated using continuous data from the neighboring gauges. The observed flows are not influenced by any upstream water structure or dam. Data homogeneity was first checked out with the double mass curve method. Mann-Kendall trend test was also performed. It was found that 22 gauges out of 40 were homogeneous and no trend was found. For the remaining 18 gauges, the non-homogeneity and/or the available trends were insignificant [20]. The most significant difference between the observed and adjusted flows was found $17.5 \%$ in Kanlipelit (No 12). Other gauges among these 18 flow gauges showed less significant differences such that mean annual flow records were used without any adjustment.

Elevation of both rain and flow gauges; flow direction and accumulation, which are the requirements of stream network; and drainage basin area of the flow gauges are delineated in Geographical Information System (GIS) environment. Digital elevation model (DEM) is produced from Shuttle Radar Topographical Mission (SRTM) with about $90 \mathrm{~m}$ resolution. Universal Transverse Mercator (UTM) coordinate system is used in the study.

\section{Method}

Kriging is a spatial interpolation technique, which incorporates spatial correlation models formulated by covariance or variogram functions. Kriging provides optimal linear estimations at ungauged points by assuming that the spatial variation of the property is a realization of a random function that has only been observed at data points [21].

The first step in the kriging process is to obtain a model of spatial autocorrelation, i.e., variogram. The 
empirical (experimental) variogram, $\gamma *(h)$, is defined as:

$$
\gamma *(h)=\frac{1}{2 N(h)} \sum_{i=1}^{N(h)}\left[z\left(x_{i}+h\right)-z\left(x_{i}\right)\right]^{2},
$$

where $h$ is the distance (also called the lag) of two observation points $z\left(x_{i}\right)$ and $z\left(x_{i}+h\right)$, and measure of $z(x)$ on locations $x_{i}$ and $x_{i}+h . N(h)$ is the total number of observation points linked by $h$.

The variogram $\gamma *(h)$ is a graph, which relates the differences of the regionalized variable $z$ to the distance $h$ between the data points. Experimental variogram is obtained using the observation points and needs to be approximated by a theoretical function $\gamma(h)$, which allows to analytically predict the variogram for any distance, $h$. The theoretical models most commonly used are Gaussian, spherical, exponential, etc., characterized by the parameters range, sill, and nugget.

Once the theoretical variogram has been fitted to the experimental one, it is possible to apply the prediction by kriging. In kriging, the estimated value $z\left(x_{0}\right)$ at location $x_{0}$ is a linear combination of observed values $z\left(x_{i}\right), i=1, \ldots, N$, located in the neighborhood of $x_{0}$ :

$$
z\left(x_{0}\right)=\sum_{i=1}^{N} \lambda_{i} z\left(x_{i}\right),
$$

where the unknowns of the equation are the weights $\lambda_{i}$. These weights are found by solving a system of linear equations, which is known as "ordinary kriging system":

$$
\left\{\begin{array}{l}
\sum_{j=1}^{N} \lambda_{j} \gamma\left(x_{i}-x_{j}\right)-\mu=\gamma\left(x_{0}-x_{i}\right) \\
\sum_{j=1}^{N} \lambda_{j}=1
\end{array}\right.
$$

In Eq. (3), $\left(x_{i}-x_{j}\right)$ represents the Euclidian distance between $x_{i}$ and $x_{j}, \gamma$ is the theoretical variogram, and $\mu$ is the Lagrangian multiplier. Ordinary kriging assumes that the random field has a constant but unknown mean. However, in practice, environmental fields often show non-constant mean values. To remedy nonstationarity problem, universal kriging is developed. Universal kriging can model tendency by some form of trend surface and then compute the semivariogram using residual values from that surface. Universal kriging system in which trend is often a function of coordinates is shown as:

$$
\left\{\begin{array}{l}
\sum_{j=1}^{N} \lambda_{j} \gamma\left(x_{i}-x_{j}\right)+\sum_{l=1}^{k} \mu_{l} f_{l}\left(x_{i}\right)=\gamma\left(x_{0}-x_{i}\right) \\
\sum_{j=1}^{N} \lambda_{j} f_{l}\left(x_{i}\right)=f_{l}\left(x_{0}\right)
\end{array}\right.
$$

where $f_{l}$ is the $l$-th basic function of spatial coordinates that describes drift, $k$ is the number of functions used in drift modeling, and $\mu_{l}$ is the Lagrangian multiplier associated with the $l$-th unbiased condition.

Detailed information about kriging method can be found in [22-24].

\section{Results and discussion}

Flow depth can be calculated by dividing total flow volume $\left(Q_{i}\right)$ for a given period at a site $i$ to basin area above the $i$-th site $\left(A_{i}\right)$. Flow depth $\left(Q_{i} / A_{i}\right)$ as a regionalized variable is uniformly distributed throughout the basin, indicating a homogeneous basin, where the increase in flow volume is proportional to enlargement of the basin area. If the stationarity hypothesis is valid, ordinary kriging is applicable. This hypothesis can be proved by investigating the relationship between flow and basin area for nested basins, i.e. the basin of one gauge is part of a larger basin contributing to another gauge [2]. However, the study area includes a mixture of nested and non-nested basins; therefore, nested basins are separated and investigated using their flow data and areas. As seen from Figure 2, flow increases with the basin area for nested basins in the region. For the coastal part of the Eastern Black Sea Region, the rainy and humid climate is responsible of abundance water resources in the basins, where both flow and flow depth increase in the downstream direction. Based on the approximate linear relationship between flow and basin area of the nested basins and climate characteristics of the region, flow depth is assumed to be homogenously distributed all over the region and, therefore, ordinary kriging can be applied.

On the other hand, being different from other meteorological variables such as precipitation, flow depth is related to basin area and represents an area instead of a point. Therefore, the representative value

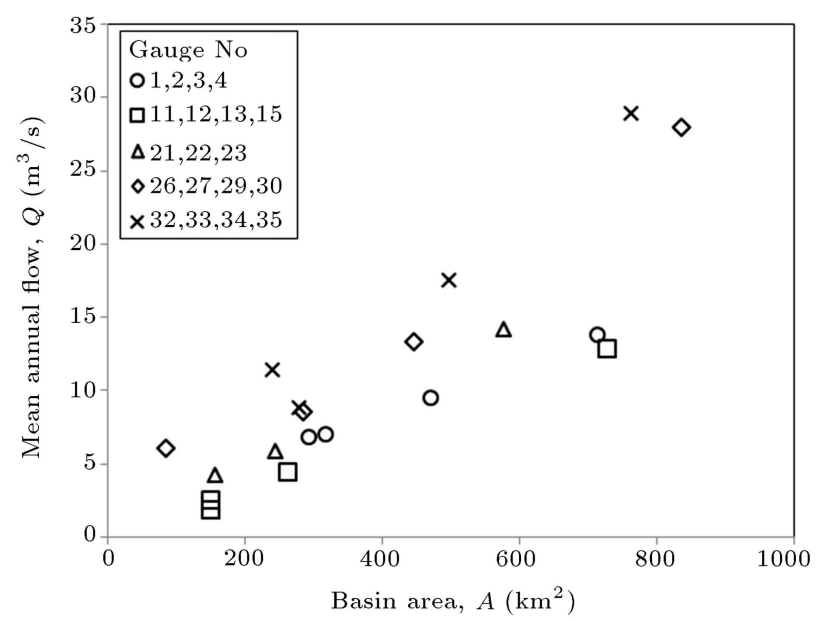

Figure 2. Relationship between flow and basin area in nested basins. 
of the flow depth is allocated on the centroid of the basin [2] instead of the actual observation location, which is the outlet of the basin. Centroids of each basin in the study area are shown in Figure 1.

As geostatistics works generally best when data have a normal distribution, flow data have been checked against normality. The data are found to be normally distributed at $\alpha$ significance level of 0.05 . In developing the empirical variogram, only the isotropy case is considered. Because of the limited data, only the omnidirectional variogram is computed, which means in all directions the spatial variabilities are assumed to be identical [25]. Theoretical model fitting is carried out using one of the most frequently applied methods, namely, cross-validation approximation. The empirical isotropic variogram and fitted model are shown in Figure 3. A Gaussian model is fitted and cross-validated with observed data. The validity of Gaussian model is verified using determination coefficient $\left(R^{2}\right)$, Root Mean Square Error (RMSE), and mean standardized residual error (MSRE), calculated as:

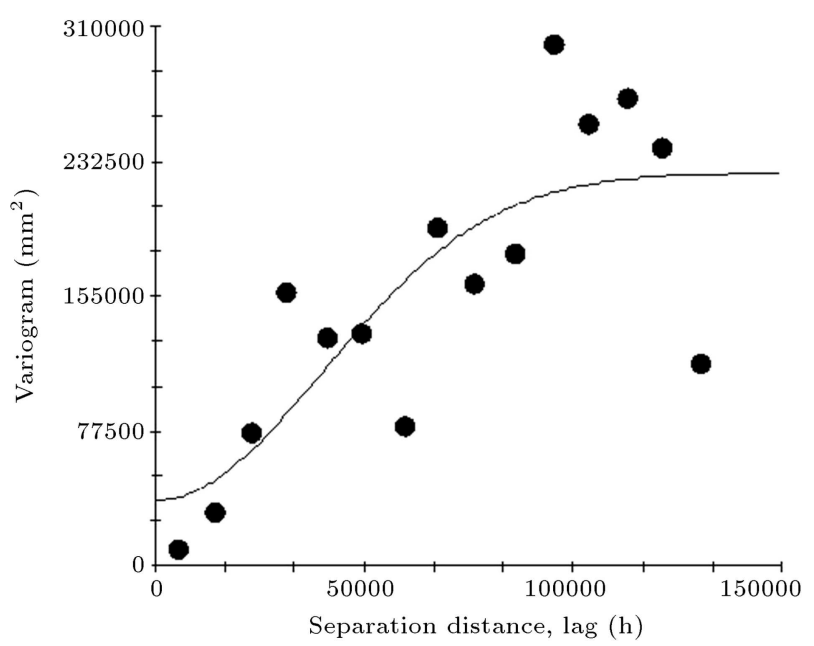

Figure 3. Experimental variogram of the flow depth with Gaussian model fitted.

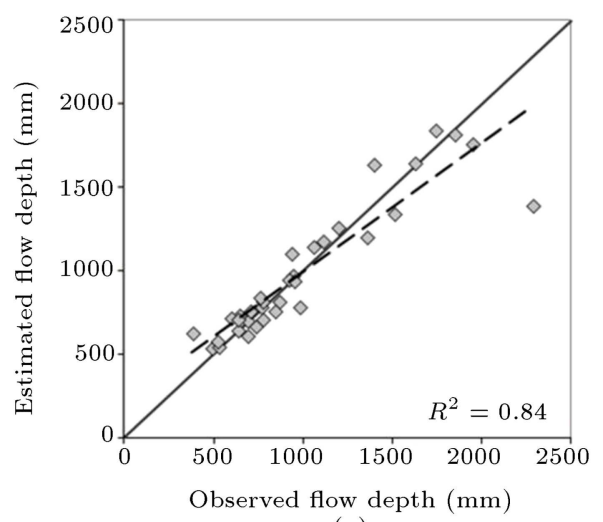

(a)

$$
\begin{aligned}
\text { RMSE } & =\left[\frac{1}{N} \sum_{i=1}^{N}\left(Q_{\mathrm{est}_{i}}-Q_{\mathrm{obs}_{i}}\right)^{2}\right]^{1 / 2}, \\
\mathrm{MSRE} & =\left[\frac{1}{N} \sum_{i=1}^{N}\left(Q_{\mathrm{est}_{i}}-Q_{\mathrm{obs}_{i}}\right) / \sigma_{i}\right],
\end{aligned}
$$

where $Q_{\text {est }}$ and $Q_{\text {obs }}$ represent estimated and observed flows, $N$ is the number of data, and $\sigma$ is the standard deviation of estimation error. The best fit of a theoretical model to an empirical variogram is achieved when MSRE approximately equals zero. On the other hand, RMSE is better for the estimation efficiency of the extremes [26,27].

Cross validation results of the observed and estimated flow depth values for ordinary kriging method are given in Table 2 and Figure 4(a). As seen from Table 2, RMSE value is $185.76 \mathrm{~mm}$ for the flow depth data of which minimum, mean, and maximum values are $382.0,996.3$, and $2284.9 \mathrm{~mm}$, respectively.

A previous study [28] has indicated that spatial distribution of precipitation on the coastal part of the Eastern Black Sea Region is not homogenous. Precipitation increases slightly with longitude, which means that the north-eastern part of the region receives greater precipitation than the western part does. Due to the amount of precipitation, flow values of the southern part are greater, i.e. a trend is observed in the flow depth data such that the average varies over the study area. As previously defined, universal kriging can incorporate the effect of the trend. The universal kriging algorithm can produce a trend model by fitting a polynomial function to the flow depth data. The locations of flow observation points are plotted on the

Table 2. Cross validation of flow depth.

\begin{tabular}{ccc}
\hline & Ordinary & Universal \\
\hline$R^{2}$ & 0.84 & 0.87 \\
RMSE $(\mathrm{mm})$ & 185.76 & 164.48 \\
MSRE & -0.059 & -0.009 \\
\hline
\end{tabular}

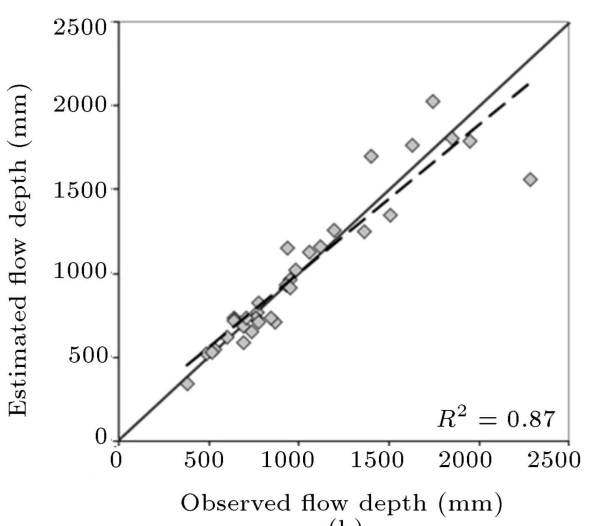

(b)

Figure 4. Cross validation of observed and estimated flow depths for (a) ordinary and (b) universal kriging. 
$x-y$ plane and depicted in Figure 5, from which a quadratic trend on the east-west direction and a linear trend on the north-south direction are observed. These trends, represented by a mathematical formula, are removed from the observations and added back before estimations are made. Cross validation results of observed and estimated flow depth values for universal kriging are given in Table 2 and Figure 4(b), after removing trends from the data. As seen from Table 2 and Figure 4, the difference in calibration between

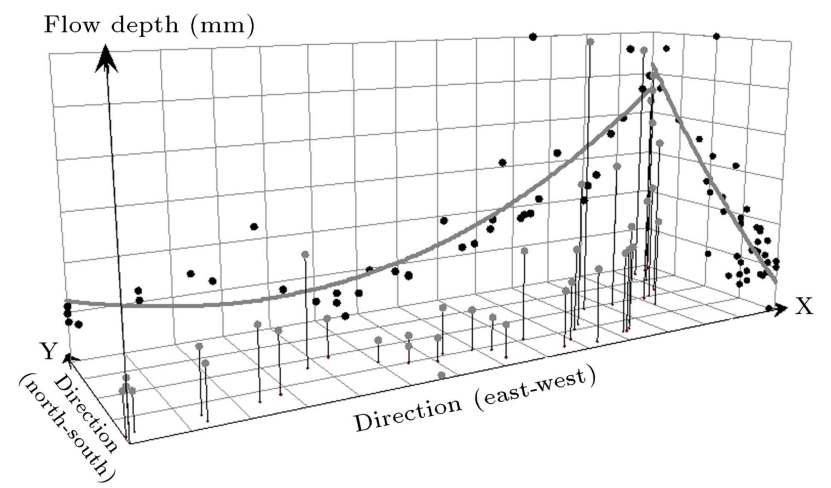

Figure 5. Trend analysis of flow depth data. ordinary and universal models is minor; however, universal method seems better based on the $R^{2}(0.87)$ and MSRE (-0.009) values.

The kriged maps of flow depth are shown in Figure 6. Streamflow maps are similar. Increase in the flow depth from west to east side of the study area is clear in both maps.

To test the validity of the flow depth map, 6 among 40 flow gauges are randomly chosen. The validation results of randomly chosen gauges are summarized in Table 3, where RE shows the relative error in percent, calculated as:

$$
\mathrm{RE}=\frac{Q_{\text {est }}-Q_{\mathrm{obs}}}{Q_{\mathrm{obs}}} \times 100 .
$$

The equivalent flow depths are multiplied by their corresponding areas and flow estimations $\left(Q_{\text {est }}\right)$ at any validation points are yielded. In the validation stage, kriging methods are compared with simple regression equation, which is shown in Figure $7 . R^{2}$ of area based regression equation is 0.70 , which is lower than that of kriging methods. Although $R^{2}$ value can be statistically accepted, this result confirms that drainage area alone is not adequate to explain regional differences in

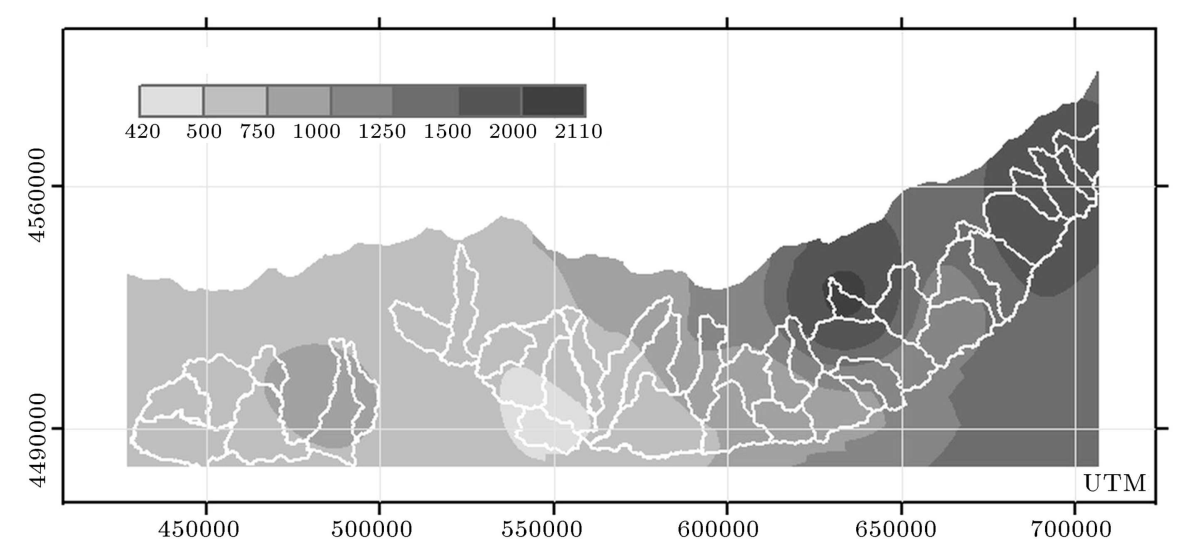

(a)

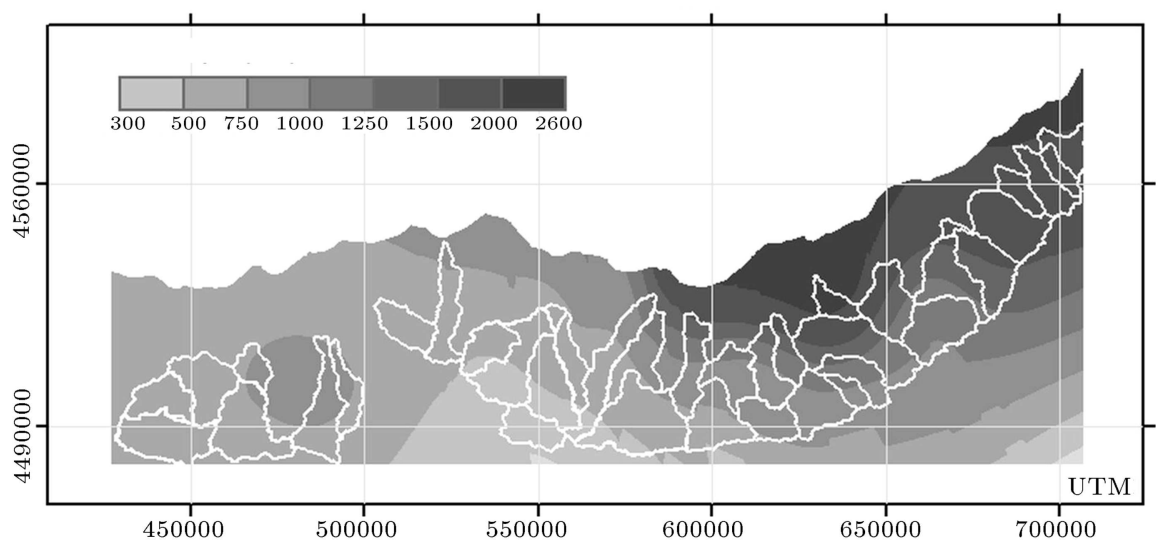

(b)

Figure 6. Streamflow maps produced using (a) ordinary and (b) universal kriging for the study area. 
Table 3. Validation results based on the streamflow maps and regression.

\begin{tabular}{ccccccccc}
\hline \multirow{2}{*}{ No } & \multirow{2}{*}{$\begin{array}{c}\text { Gauge } \\
\boldsymbol{Q}_{\text {obs }}\end{array}$} & \multicolumn{6}{c}{$\boldsymbol{Q}_{\text {est }}\left(\mathbf{m}^{\mathbf{3}} / \mathbf{s}\right)$} \\
\cline { 6 - 10 } & name & $\left(\mathbf{m}^{\mathbf{3}} / \mathbf{s}\right)$ & \multicolumn{2}{c}{ Ordinary } & \multicolumn{2}{c}{ Universal } & \multicolumn{2}{c}{ Regression } \\
\hline 4 & Dereli & 13.80 & 15.04 & $(8.95)$ & 15.15 & $(9.8)$ & 20.09 & $(45.7)$ \\
9 & Cucenkopru & 5.68 & 3.42 & $(-39.8)$ & 3.29 & $(-42.0)$ & 5.07 & $(-10.6)$ \\
13 & Ogutlu & 12.85 & 11.80 & $(-8.14)$ & 11.73 & $(-8.7)$ & 20.52 & $(59.7)$ \\
18 & Agnas & 12.20 & 13.93 & $(14.2)$ & 13.99 & $(14.7)$ & 17.98 & $(47.4)$ \\
32 & Cat & 8.79 & 9.98 & $(13.5)$ & 8.96 & $(1.91)$ & 8.21 & $(-6.65)$ \\
37 & Arili & 6.32 & 5.06 & $(-20.0)$ & 5.27 & $(-16.6)$ & 3.15 & $(-50.2)$ \\
\hline
\end{tabular}

Note: Parentheses represent relative errors (RE\%).

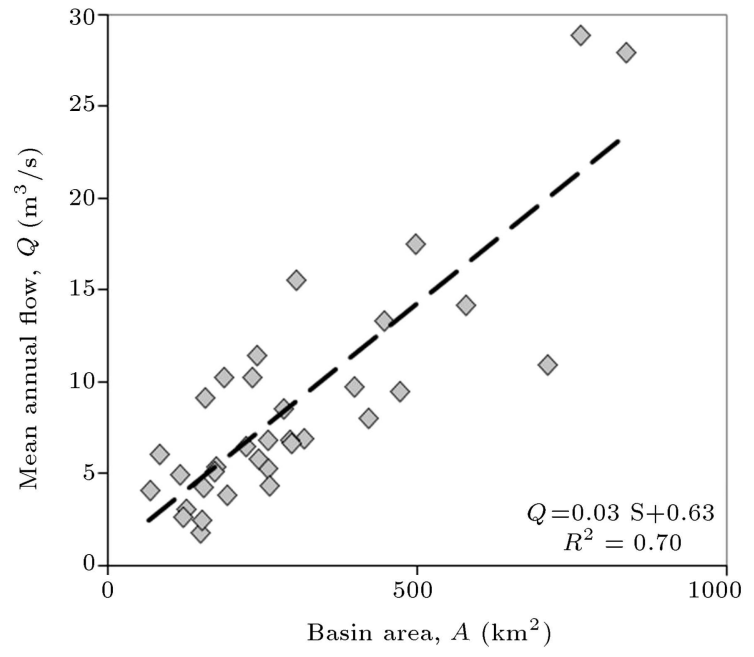

Figure 7. Simple regression relationship between flow data and basin area.

annual streamflow [29]. In addition, $R^{2}$ seems to be partially controlled by the position of greater values (points on upper right position in Figure 7), which indicates an unstable situation [30].

In the validation stage, minimum and maximum relative errors are -39.8 and 14.2 in ordinary, -42.0 and 14.7 in universal, and -50.2 and 59.7 in regression equations. Relative errors are high in low flow estimations; as a comparison criterion, it seems to be meaningless and, therefore, the Absolute Error (AE), which is the difference between estimation and observation, can be accepted. For the gauge Cucenkopru (No 9), which has the highest RE, AEs are found to be 2.26 and $-2.39 \mathrm{~m}^{3} / \mathrm{s}$ in ordinary and universal models, respectively. The validation results appear satisfactory in terms of kriging methods.

\section{Conclusion}

In this study, to determine spatial variation of flow, streamflow maps were produced for the coastal part of the Eastern Black Sea Region, Turkey. The mean annual flow depth was considered as a regionalized variable, thus ordinary and universal kriging methods could be applied.

Mean annual flow depth was obtained using mean annual flow observation, which represents the difference between annual evaporation and precipitation and provides a measure of the overall water resource for a region. It gives valuable information on the basin under consideration and is useful for comparing water amount in one basin with that in another one. It is used for surface water hydrology and hydrologic design, and characterizes the flow regime in a stream.

In this study, two kriging methods were used. Ordinary kriging is commonly used in practice and has various applications in streamflow estimation studies. On the other hand, universal kriging assumes that a trend is available over the area. Universal kriging is also performed when there is spatial variability of the precipitation in the study area.

Kriging methods were compared with simple regression based on the relationship between flow data and basin area. From this study, the following conclusions can be drawn:

- Kriging application of mean annual flow depth provided satisfactory results, meaning that it was useful for flow data at annual time scale;

- The performance of kriging models was superior to that of the regression model based on the flow data and basin area relationship. Considering calibration results, universal kriging was better than ordinary kriging, but the difference was not statistically significant;

- The flow depth map can be a useful tool for flow estimation on ungauged locations in the Eastern Black Sea Region. Promising results of calibration and validation encourage one to suggest this method for other hydrologic applications in different regions in Turkey. 


\section{Acknowledgements}

This study has been supported by the Scientific and Technical Research Council of Turkey, under project number TUBITAK 106M043. The authors would like to thank the anonymous reviewers for their valuable comments and suggestions to improve the quality of the paper.

\section{References}

1. Milly, P.C.D. and Dunne, K.A. "Macroscale water fluxes: 1. Quantifying errors in the estimation of basin mean precipitation", Water Resour. Res., 38(10), pp. 1-14 (2002).

2. Huang, W.C. and Yang, F.T. "Streamflow estimation using Kriging”, Water Resour. Res., 34(6), pp. 15991608 (1998).

3. Rochelle, B.P., Stevens Jr., D.L., and Church, M.R. "Uncertainty analysis of runoff estimates from a runoff contour map", Water Resour. Bull., 25, pp. 491-498 (1989).

4. Krug, W.R., Gebert, W.A., Graczyk, D.J., Stevens, D.L., Rochelle, B.P., and Church, M.R. "Map of mean annual runoff for the northeastern, southeastern, and mid-Atlantic United States Water Years 1951-80", U.S. Geological Survey Water Resources Investigations Report, Madison, WI (1990).

5. Bishop, G.D. and Church, M.R. "Automated approaches for regional runoff mapping in the northeastern United States", J. Hydrol., 138, pp. 361-383 (1992).

6. Merz, R. and Bloschl, G. "Flood frequency regionalisation - spatial proximity vs. catchment attributes", J. Hydrol., 302, pp. 283-306 (2005).

7. Arnell, N.W. "Grid mapping of river discharge", $J$. Hydrol., 167, pp. 39-56 (1995).

8. Gottschalk, L. "Correlation and covariance of runoff", Stoch. Hydrol. Hydraulics., 7(2), pp. 85-101 (1993).

9. Gottschalk, L. "Interpolation of runoff applying objective methods", Stoch. Hydrol. Hydraulics., 7(4), pp. 269-281 (1993).

10. Sauquet, E., Gottschalk, L., and Leblois, E. "Mapping average annual runoff: A hierarchical approach applying a stochastic interpolation scheme", Hydrol. Sci. J., 45, pp. 799-816 (2000).

11. Sauquet, E. "Mapping mean annual river discharges: Geostatistical developments for incorporating river network dependencies", J. Hydrol., 331, pp. 300-314 (2006).

12. Sauquet, E., Gottschalk, L., and Krasovskaia, I. "Estimating mean monthly runoff at ungauged locations: An application to France", Hydrol. Res., 39(5-6), pp. 403-423 (2008).

13. Skoien, J.O., Merz, R., and Blöschl, G. "Top-kriging geostatistics on stream networks", Hydrol. Earth Syst. Sci., 10, pp. 277-287 (2006).
14. Laaha, G., Skoien, J.O., and Blöschl, G. "Spatial prediction on river networks: Comparison of topkriging with regional regression", Hydrol. Process., 28, pp. 315-324 (2014).

15. Archfield, S.A., Pugliese, A., Castellarin, A., Sk $\phi$ ien, J.O. and Kiang, J.E. "Topological and canonical kriging for design flood prediction in ungauged catchments: an improvement over a traditional regional regression approach?", Hydrol. Earth Syst. Sci., 17, pp. 15751588 (2013).

16. Pugliesse, A., Farmer, W.H., Castellarin, A., Archfield, S.A., and Vogel, R.M. "Regional flow duration curves: Geostatistical techniques versus multivariate regression", Adv. Water Resour., 96, pp. 11-22 (2016).

17. Yan, Z., Xia, J., and Gottschalk, L. "Mapping runoff based on hydro-stochastic approach for the Huaihe River Basin, China", J. Geogr. Sci., 21(3), pp. 441457 (2011).

18. Kaygusuz, K. and Sari, A. "Renewable energy potential and utilization in Turkey", Energ. Convers. Manag, 44, pp. 459-478 (2003).

19. Eris, E. "Determination of spatial distribution of precipitation on poorly gauged coastal regions", $\mathrm{PhD}$ Thesis, Istanbul Technical University, Institute of Science and Technology (2011).

20. Eris, E. and Agiralioglu, N. "Homogeneity and trend analysis of hydrometeorological data of the eastern black sea region, Turkey", JWARP, 4, pp. 99-105 (2012).

21. Sima, S. and Tajrishy, M. "Developing water quality maps of a hyper-saline lake using spatial interpolation methods", Sci. Iran., 22(1), pp. 30-46 (2015).

22. Isaaks, E.H. and Srivastava, R.M., Applied Geostatistics, Oxford University Press, NY (1989).

23. Goovaerts, P., Geostatistics for Natural Resources Evaluation, Oxford University Press, NY (1997).

24. Journel, A.G. and Huijbregts, Ch.J., Mining Geostatistics, The Blackburn Press, NJ (2003).

25. Goovaerts, P. "Geostatistical approaches for incorporating elevation into the spatial interpolation of rainfall", J. Hydrol., 228, pp. 113-129 (2000).

26. Gyalistras, D. "Development and validation of a high resolution monthly gridded temperature and precipitation data set for Switzerland (1951-2000)", Clim. Res., 25, pp. 55-83 (2003).

27. Vicente-Serrano, S.M., Saz-Sanchez, M.A. and Cuadrat, J.M. "Comparative analysis of interpolation methods in the Middle Ebro Valley (Spain): Application to annual precipitation and temperature", Clim. Res., 24, pp. 161-180 (2003).

28. Eris, E. and Agiralioglu, N. "Effect of coastline configuration on precipitation distribution in coastal zones", Hydrol. Process., 23(25), pp. 3610-3618 (2009).

29. Vogel, R.M., Wilson, I. and Daly, C. "Regional regression models of annual streamflow for the United States", J. Irrig. Drain. Eng., 125(3), pp. 148-157 (1999). 
30. Helsel, D.R. and Hirsch, R.M., Statistical Methods in Water Resources Techniques of Water Resources Investigations, Book 4, chapter A3. U.S. Geological Survey (2002).

\section{Biographies}

Ebru Eris, born in 1979 in Izmir, Turkey, received her BSc and MSc degrees from Ege University and $\mathrm{PhD}$ degree from Istanbul Technical University. She is currently working as an Assistant Professor in the Department of Civil Engineering, Ege University. She is co-author of 10 international scientific publications and more than 50 international and national proceeding papers. She is Vice-President of International Commission of Statistical Hydrology (STAHY) of the International Association of Hydrological Sciences and Secretary of Hidroist (Statistical Hydrology Working Group of the Turkish National Hydrology Commission). She has been involved in national and international activities, including an international project, bilaterally funded by The Scientific and Technological Research Council of Turkey (TUBITAK) and the National Research Foundation of Korea (NRF); she was also scientific committee member of the 3rd STAHY
International Workshop on Statistical Methods; organizing Committee member of the 5th EGU Leonardo Conference, Facets of Uncertainty; and a co-convener of IAHS symposia and workshops in the 26th IUGG General Assembly. She worked as a guest researcher at the LEUPHANA, University of Lüneburg, Germany, between October 2014 and June 2015.

Necati Agiralioglu was born in 1947. He received his MSc and PhD from Istanbul Technical University (ITU), Turkey. From 1978 to 1979, he was a researcher at the Colorado State University and Mississippi State University. In 1988, he became Professor in the Civil Engineering Department at ITU. He started to serve as a dean of Sakarya University in 1993. Between the years 2003 and 2009, he was chairman of the Hydraulics Department at ITU. In the 5th World Water Forum, he acted as a Programme Committee Co-Chair. Also, he has worked as a board member of Istanbul Water Supply and Sewerage Administration. He is author/coauthor of 9 books and 35 SCI papers, out of more than 140 scientific publications. He has completed various scientific or technical projects and worked as a consultant. Also, he has supervised 13 $\mathrm{PhD}$ dissertations and more than $35 \mathrm{MSc}$ theses. 